\title{
Blood lactate level during extracorporeal life support as a surrogate marker for survival
}

\author{
Sung Jun Park, MD, ${ }^{a}$ Sang-pil Kim, MD, PhD, ${ }^{b}$ Joon Bum Kim, MD, PhD, ${ }^{\text {a }}$ Sung-Ho Jung, MD, PhD, \\ Suk Jung Choo, MD, PhD, ${ }^{a}$ Cheol Hyun Chung, MD, PhD, ${ }^{a}$ and Jae Won Lee, MD, PhD ${ }^{\mathrm{a}}$
}

\begin{abstract}
Objective: The establishment of reliable markers to monitor adequate tissue perfusion during extracorporeal life support is clinically important to improve outcomes.
\end{abstract}

\begin{abstract}
Methods: We evaluated 115 consecutive adult patients (aged $61.7 \pm 13.4$ years, 59 female patients) undergoing extracorporeal life support to manage low cardiac output syndrome after major cardiac surgery. The blood lactate levels serially measured during extracorporeal life support (at 6, 12, and 24 hours) were analyzed.
\end{abstract}

\begin{abstract}
Results: Forty-seven patients (40.8\%) were weaned off extracorporeal life support successfully, and 32 patients $(27.8 \%)$ survived to discharge. On logistic regression analysis, a high blood lactate level before extracorporeal life support (relative risk [RR], 1.19; 95\% confidence interval [CI], 1.06-1.34) and cardiopulmonary bypass weaning failure after surgery (RR, 4.39; $95 \% \mathrm{CI}, 1.44-13.35)$ emerged as baseline risk factors of mortality. After adjustment with these factors, blood lactate levels at 6 hours (RR, 1.24; 95\% CI, 1.06-1.46), 12 hours (RR, 1.35; 95\% CI, 1.10-1.67), and 24 hours (RR, 1.46; 95\% CI, 1.10-1.93) were predictive of mortality. When the predictive values of serial blood lactate levels for mortality were assessed using the receiver operating characteristic method, the greatest accuracy was obtained at cutoff values of $7.05 \mathrm{mmol} / \mathrm{L}$ at 6 hours (sensitivity, $75.5 \%$; specificity, $75.0 \%$ ), $4.95 \mathrm{mmol} / \mathrm{L}$ at 12 hours (sensitivity, $70.4 \%$; specificity, $76 \%$ ), and $4.15 \mathrm{mmol} / \mathrm{L}$ at 24 hours (sensitivity, 62\%; specificity, 93.1\%).

Conclusions: Blood lactate measurement can be used as a reliable tool for monitoring adequate tissue perfusion during extracorporeal life support and was strongly predictive of mortality. Therefore, in patients without adequate decrement in lactate levels during extracorporeal life support, potential factors responsible for inadequate perfusion should be identified and corrected. (J Thorac Cardiovasc Surg 2014;148:714-20)
\end{abstract}

With the technologic advancement of extracorporeal life support (ECLS) and improvement in its management strategies, the use of ECLS has been generalized in clinical practice over the past decade. ECLS can provide total circulatory support with fully oxygenated blood so that systemic tissue perfusion is satisfied in patients with severe respiratory or circulatory failure. Nevertheless, achieving adequate tissue perfusion can be disturbed by unexpected clinical situations, such as device-related problems, cannulation-related complications, and hemorrhagic events. These situations may lead to tissue hypoperfusion and consequent end-organ damage, ultimately hampering the outcomes of ECLS. ${ }^{1,2}$ In these regards, early detection

From the Department of Thoracic and Cardiovascular Surgery, ${ }^{\mathrm{a}}$ Asan Medical Center, University of Ulsan College of Medicine, Seoul, Korea; and Department of Thoracic and Cardiovascular Surgery, ${ }^{\mathrm{b}}$ Pusan National University Hospital, Busan, Korea.

Disclosures: Authors have nothing to disclose with regard to commercial support. Drs Park and Kim contributed equally as first authors in this article.

Received for publication Oct 23, 2013; revisions received Jan 30, 2014; accepted for publication Feb 26, 2014; available ahead of print March 28, 2014.

Address for reprints: Joon Bum Kim, MD, PhD, Department of Thoracic and Cardiovascular Surgery, Asan Medical Center, University of Ulsan College of Medicine, 388-1 Pungnap-dong Songpa-gu, Seoul 138-736, South Korea (E-mail: jbkim1975@amc.seoul.kr).

0022-5223/\$36.00

Copyright (c) 2014 by The American Association for Thoracic Surgery

http://dx.doi.org/10.1016/j.jtcvs.2014.02.078 of suboptimal tissue perfusion despite the ECLS implementation will be clinically important to identify correctable factors of hypoperfusion and thereby to improve the outcomes. Nonetheless, the reliable monitoring markers of adequate tissue perfusion during ECLS have not been established to date.

High lactate level is known to be an independent predictor of low cardiac output syndrome and major complications after cardiac surgery. ${ }^{3,4}$ Blood lactate level can be promptly measured in intensive care unit (ICU) settings from simple arterial blood gas analysis (ABGA) samplings. In this study, we hypothesized that arterial blood lactate level during ECLS can be used as a reliable predictive marker of mortality. Therefore, we sought to evaluate the role of serially measured arterial lactate level during ECLS as a monitoring tool for tissue perfusion in the setting of post-cardiac surgery ECLS.

\section{METHODS \\ Patients \\ Between May 2005 and December 2012, 10,197 adult patients underwent major cardiac surgery at the Asan Medical Center, Seoul, Korea. These surgeries included valve surgery, coronary artery bypass grafting, aortic surgery, resection of cardiac tumors, pericardiectomy, pulmonary thromboembolectomy, and heart transplantation. Of these patients, 125 were supported with venoarterial-type ECLS for low cardiac output}



Abbreviations and Acronyms
$\mathrm{ABGA}=$ arterial blood gas analysis
$\mathrm{CI}=$ confidence interval
$\mathrm{CPB}=$ cardiopulmonary bypass
ECLS = extracorporeal life support
ICU = intensive care unit
ROC $=$ receiver operating characteristic
$\mathrm{RR} \quad=$ relative risk

syndrome after major cardiac surgery at the Asan Medical Center, Seoul, Korea. After exclusion of 10 patients who underwent preoperative ECLS, 115 patients were included in this study. Clinical situations that required postoperative ECLS were as follows: (1) 48 patients with usual postoperative low cardiac output syndrome that was unresponsive to inotropics or intra-aortic balloon pumping, (2) 27 patients with witnessed cardiac arrest that was unresponsive to standard advanced cardiopulmonary life support, and (3) 40 patients with postoperative cardiopulmonary bypass (CPB) weaning failure.

The study was approved by the institutional ethics committee/review board of the University of Ulsan, and the requirement for informed patient consent was waived in view of the retrospective nature of the study.

\section{Extracorporeal Life Support Devices and Management}

Venoarterial ECLS was implemented at the common femoral artery and vein or internal jugular vein using the Seldinger technique in all 115 patients. The ECLS system consisted of a centrifugal pump, a hollow fiber membrane oxygenator with an integral heat exchanger, and a heparin-bound circuit. Three types of ECLS system were used: the Capiox Emergent Bypass System (Terumo Corp, Tokyo, Japan) was used for 94 patients $(81.7 \%)$, the PLS System (Maquet, Hirrlingen, Germany) was used for 14 patients $(12.2 \%)$, and the Bio-Console 560 System (Medtronic, Inc, Minneapolis, Minn) was used for 7 patients $(6.1 \%)$.

Blood lactate level measurement was performed routinely every 2 to 3 hours from simple ABGA samples. The ABGA samples were analyzed by GEM Premier 3000 (Instrumentation Laboratory, Lexington, Mass).

An intravenous heparin bolus of $100 \mathrm{U} / \mathrm{kg}$ was administered to achieve a celite activated clotting time (measured using a Hemochron 401 machine, Soma Technology, Bloomfield, Conn) of 300 seconds before cannulation of arterial and venous catheter. After the initiation of ECLS, the activated clotting time was maintained within a range of 180 to 200 seconds. From 2010, nafamostat mesilate (Futhan; Torii Pharmaceutical, Tokyo, Japan), a synthetic serine protease inhibitor, was adopted to use as an alternative anticoagulant to heparin for patients with a high risk of bleeding. For these patients, a half-dose of heparin was administered before cannulation, and activated clotting time was maintained within 160 to 180 seconds after the administration of a starting dose of $0.75 \mathrm{mg} / \mathrm{kg}$ nafamostat mesilate. The patients $(n=5)$ with severe coagulopathy in the immediate postoperative period were not administered heparin or nafamostat mesilate until the bleeding was controlled. The details of coagulation strategy during ECLS and ECLS weaning protocol have been described.

We tried to maintain the ECLS blood flow greater than the cardiac index of $2.4 \mathrm{~L} / \mathrm{min} / \mathrm{m}^{2}$. To maintain the mean arterial pressure of 60 to $70 \mathrm{~mm} \mathrm{Hg}$, vasopressors such as norepinephrine or vasopressin were administered as needed. Red blood cells and platelets were transfused to maintain the hematocrit of $30 \%$ to $35 \%$ and platelet count greater than $100 \times 10^{3} / \mathrm{mm}^{3}$ for patients with a high bleeding risk. An antegrade perfusion catheter for distal limb perfusion was routinely placed distal to the arterial cannulation site, except in the case of the failure to implant the catheter because of technical difficulties.

\section{Statistical Analysis}

Categoric variables are presented as frequencies and percentages, and were compared using the Chi-square test or Fisher exact test. Continuous variables are expressed as mean \pm standard deviation and were compared using the Student unpaired $t$ test. To determine the baseline risk factors for mortality, logistic regression models were used. At the first stage of the analyses, baseline characteristics of patients and variables related to ECLS were considered in the logistic regression model. Variables with a $P$ value of .20 or less in univariable analyses were candidates for the multivariable models. Multivariable analyses involved a backward elimination technique, and only variables with a $P$ value of .10 or less were used in the final model. To evaluate the impact of post-ECLS lactate level on death, further multivariable analyses were conducted that involved serial post-ECLS lactate levels at each point and significant variables affecting mortality in the second stage of the analyses. Results were expressed as a relative risk (RR) with $95 \%$ confidence intervals (CIs). The predictive value of post-ECLS lactate level for mortality was evaluated by analyzing areas under receiver operating characteristic (ROC) curves, with their 95\% CI. The optimal cutoff value corresponded to the value with the greatest accuracy. Survival was estimated by the Kaplan-Meier method and compared by the log-rank test. All reported $P$ values are 2-sided. Statistical analyses were performed with SPSS 18.0 for Windows Software (IBM, Armonk, NY).

\section{RESULTS}

The baseline characteristics and clinical data related to ECLS of the patients are shown in Tables 1 and 2, respectively. The patients who died in-hospital required a longer $\mathrm{CPB}$ time during surgery and were more likely to undergo ECLS at the end of the operation because of CPB weaning failure than those who survived to discharge, whereas there were no significant differences between the 2 groups in other baseline profiles. The levels of arterial blood lactate before and after the initiation of ECLS were significantly higher in patients who died in-hospital compared with those in the group of survivors to discharge.

Sixty-three patients $(54.8 \%)$ experienced at least 1 complication during ECLS. Table 3 provides the details of complications that occurred during ECLS. The serial blood lactate levels at 6 hours $(9.73 \pm 4.48$ vs $7.01 \pm 4.39$; $P=.007), 12$ hours $(8.10 \pm 4.76$ vs $5.14 \pm 3.74$; $P=.003)$, and 24 hours $(6.48 \pm 4.98$ vs $4.00 \pm 2.92$; $P=.008)$ after ECLS initiation were significantly higher in the patients who had at least 1 complication $(n=63)$ than the patients without complications $(n=52)$. The incidence rates of overall complications were significantly higher in patients who died in-hospital than those who survived to discharge $(P=.003)$.

The overall outcomes of ECLS are summarized in Figure 1. Two patients underwent successful heart transplantation and survived to discharge. Forty-seven patients $(40.8 \%)$ were weaned off ECLS successfully; however, 17 patients died after successful weaning from ECLS in-hospital. The cause of death after successful weaning was multiple organ failure in 6 patients, profound cardiac failure in 3 patients, sepsis in 2 patients, pan-peritonitis in 2 patients, aortic rupture in 2 patients, 
TABLE 1. Baseline characteristics of patients who underwent extracorporeal life support after major cardiac surgery

\begin{tabular}{|c|c|c|c|c|}
\hline Variables & Total $(n=115)$ & Discharged $(n=32)$ & Died in-hospital $(\mathbf{n}=\mathbf{8 3})$ & $P$ value \\
\hline Age, y & $61.7 \pm 13.4$ & $58.2 \pm 16.1$ & $63.0 \pm 11.9$ & .088 \\
\hline Male gender, n (\%) & $56(48.7)$ & $16(50)$ & $40(48.2)$ & .83 \\
\hline Body surface area, $\mathrm{m}^{2}$ & $1.65 \pm 0.19$ & $1.60 \pm 0.18$ & $1.66 \pm 0.20$ & .24 \\
\hline Hypertension, $\mathrm{n}(\%)$ & $53(46.1)$ & $12(37.5)$ & $41(49.4)$ & .40 \\
\hline Diabetes mellitus, n (\%) & $23(20)$ & $6(18.8)$ & $17(20.5)$ & $>.99$ \\
\hline \multicolumn{5}{|l|}{ Echocardiographic data } \\
\hline LV end-systolic dimension, mm & $36.4 \pm 11.5$ & $38.5 \pm 14.5$ & $35.5 \pm 10.2$ & .26 \\
\hline LV end-diastolic dimension, $\mathrm{mm}$ & $53.1 \pm 9.6$ & $54.2 \pm 11.6$ & $52.7 \pm 8.8$ & .48 \\
\hline LV ejection fraction, $\%$ & $57.1 \pm 14.3$ & $51.7 \pm 16.7$ & $55.0 \pm 13.3$ & .22 \\
\hline LV mass, $\mathrm{g}$ & $192.4 \pm 73.8$ & $186.4 \pm 67.3$ & $194.8 \pm 76.4$ & .54 \\
\hline Operation type & & & & .49 \\
\hline Valve surgery, n (\%) & $31(30.0)$ & $10(31.3)$ & $21(25.3)$ & \\
\hline CABG, $\mathrm{n}(\%)$ & $25(21.7)$ & $8(25)$ & $17(20.5)$ & \\
\hline Valve + CABG, n (\%) & $15(13.0)$ & $2(6.3)$ & $13(15.7)$ & \\
\hline Aorta surgery, $\mathrm{n}(\%)$ & $9(7.8)$ & $2(6.3)$ & $7(8.4)$ & \\
\hline Aorta + valve or CABG, $\mathrm{n}(\%)$ & $18(15.7)$ & $3(9.4)$ & $15(18.1)$ & \\
\hline Others, n $(\%)$ & $17(14.8)$ & $7(21.9)$ & $10(12.0)$ & \\
\hline Previous cardiac surgery, $\mathrm{n}(\%)$ & $14(12.2)$ & $2(6.3)$ & $12(14.5)$ & .34 \\
\hline ACC time, $\min$ & $104.7 \pm 83.5$ & $109.5 \pm 76.3$ & $102.9 \pm 86.6$ & .98 \\
\hline $\mathrm{CPB}$ time, $\min$ & $232.4 \pm 134.0$ & $190.0 \pm 85.9$ & $248.6 \pm 146.1$ & .014 \\
\hline
\end{tabular}

Values are $\mathrm{n}(\%)$ or mean $\pm \mathrm{SD}$. $A C C$, Aortic crossclamp; $C A B G$, coronary arterial bypass grafting; $C P B$, cardiopulmonary bypass; $L V$, left ventricular.

intracerebral hemorrhage in 1 patient, and gastrointestinal bleeding in 1 patient. Consequently, including 2 heart transplantation recipients, 32 patients $(27.8 \%)$ survived to discharge.

On logistic regression analysis, a high blood lactate level before ECLS (RR, 1.19; 95\% CI, 1.06-1.34) and CPB weaning failure after surgery (RR, 4.39; 95\% CI, 1.44-13.35) emerged as significant and independent baseline risk factors of mortality (Table 4).

After adjustment with these baseline risk factors, high blood lactate levels at 6 hours (RR, 1.24; 95\% CI, 1.061.46), 12 hours (RR, 1.35; 95\% CI, 1.10-1.67), and 24 hours (RR, 1.46; 95\% CI, 1.10-1.93) after the initiation of ECLS were significantly predictive of mortality (Table 4). The predictive values of serial blood lactate levels after the initiation of ECLS for mortality were assessed using the ROC method. The greatest accuracy for prediction of mortality was obtained at cutoff values of $7.05 \mathrm{mmol} / \mathrm{L}$ at 6 hours (sensitivity, 75.5\%; specificity, 75.0\%), 4.95 $\mathrm{mmol} / \mathrm{L}$ at 12 hours (sensitivity, 70.4\%; specificity, $76 \%$ ), and $4.15 \mathrm{mmol} / \mathrm{L}$ at 24 hours (sensitivity, 62\%; specificity, 93.1\%), showing an area under curve of 0.76 at 6 hours, 0.79 at 12 hours, and 0.76 at 24 hours after the initiation of ECLS (Figure 2).

Complications tended to occur less frequently in patients whose lactate level was below the cutoff value than those whose lactate level was greater than the cutoff value at each point (Figure 3).

The differences in survival according to the arterial blood lactate levels after the initiation of ECLS are illustrated in Figure 4. Survivals were higher in the patients whose arterial blood lactate level was below the cutoff values

TABLE 2. Extracorporeal life support data

\begin{tabular}{|c|c|c|c|c|}
\hline Variables & Total $(n=115)$ & Discharged $(\mathbf{n}=32)$ & Died in-hospital $(n=83)$ & $P$ value \\
\hline \multicolumn{5}{|l|}{ Clinical situation of ECLS implantation } \\
\hline At the end of operation, $\mathrm{n}(\%)$ & $41(35.7)$ & $6(18.8)$ & $35(42.2)$ & .029 \\
\hline Arrest, n (\%) & $27(23.5)$ & $7(21.9)$ & $20(24.1)$ & .80 \\
\hline Interval from operation finish to ECLS, $h$ & $13.5(0.6-701.9)$ & $11.3(0.8-50.8)$ & $14.1(0.6-701.9)$ & .051 \\
\hline \multicolumn{5}{|l|}{ Blood lactate level, mmol/L } \\
\hline Before initiating ECLS & $9.07 \pm 4.59$ & $7.33 \pm 3.90$ & $9.78 \pm 4.67$ & .002 \\
\hline $6 \mathrm{~h}$ after ECLS initiation & $8.47 \pm 4.61$ & $5.81 \pm 3.47$ & $9.92 \pm 4.54$ & $<.001$ \\
\hline $12 \mathrm{~h}$ after ECLS initiation & $6.73 \pm 4.54$ & $3.77 \pm 2.19$ & $8.16 \pm 4.70$ & $<.001$ \\
\hline $24 \mathrm{~h}$ after ECLS initiation & $5.27 \pm 4.27$ & $2.87 \pm 1.28$ & $6.71 \pm 4.77$ & $<.001$ \\
\hline Duration of ECLS, $\mathrm{h}$ & $71.3(0.5-712.9)$ & $70(0.8-460)$ & $71.9(0.5-712.9)$ & .29 \\
\hline Use of nafamostat anticoagulant, n (\%) & $26(22.6)$ & $11(34.4)$ & $15(18.1)$ & .12 \\
\hline
\end{tabular}

Values are $\mathrm{n}(\%)$ mean \pm standard deviation or median (range). ECLS, Extracorporeal life support. 
TABLE 3. Early outcomes of patients who underwent extracorporeal life support

\begin{tabular}{lc}
\hline & Total $(\mathbf{n}=\mathbf{1 1 5})$ \\
\hline In-hospital death, $\mathrm{n}(\%)$ & $83(72.2)$ \\
Successful weaning, $\mathrm{n}(\%)$ & $47(40.8)$ \\
No. of patients with complications during ECLS & \\
$\quad$ Mediastinal bleeding, n (\%) & $42(36.5)$ \\
$\quad$ Reoperation for bleeding & $31(27.0)$ \\
$\quad$ Massive bleeding (not operated) & $11(9.6)$ \\
Lower limb ischemia, $\mathrm{n}(\%)$ & $19(16.5)$ \\
Bowel ischemia, n (\%) & $8(7.0)$ \\
Cannulation-related complications, $\mathrm{n}(\%)$ & $13(11.3)$ \\
\hline
\end{tabular}

Values are $\mathrm{n}(\%)$. ECLS, Extracorporeal life support.

than in the patients whose lactate level was greater than cutoff values at each point.

\section{DISCUSSION}

Although the establishment of reliable markers to monitor adequate tissue perfusion during ECLS is clinically important to improve outcomes, clinical studies regarding monitoring tools during ECLS have been rare to date. Because reduced arterial pulse pressure is known to be indicative of decreased left ventricular systolic function, ${ }^{6}$ a recent study suggested arterial pulse pressure as a prognostic marker for mortality in patients receiving ECLS. ${ }^{7}$ However, arterial pulse pressure neither reflects the degree of tissue perfusion nor has an indeterminate nature; therefore, its use as a reliable monitoring tool during ECLS is doubtful.

Mixed venous oxygen saturation, a commonly used monitoring parameter in ICU, measured from the pulmonary artery, represents the balance between oxygen delivery and consumption. ${ }^{8}$ A significant proportion of patients receiving ECLS are typically seriously collapsed in hemodynamics at the time of ECLS. Consequently, peripheral arteriovenous shunt and blockade of oxygen delivery frequently appear in those patients. In this situation, mixed venous oxygen saturation is known to be unreliable and inadequate to monitor tissue perfusion. Furthermore, early detection and identification of endorgan injury, and consequences of the tissue hypoxia, are not available.

Pyruvate, intermediate metabolite of glycolysis, is converted to lactate by lactate dehydrogenase in anaerobic condition. The normal plasma lactate level is generally kept at 0.3 to $1.3 \mathrm{mmol} / \mathrm{L}$, which represents a balance between lactate production and removal. However, tissue

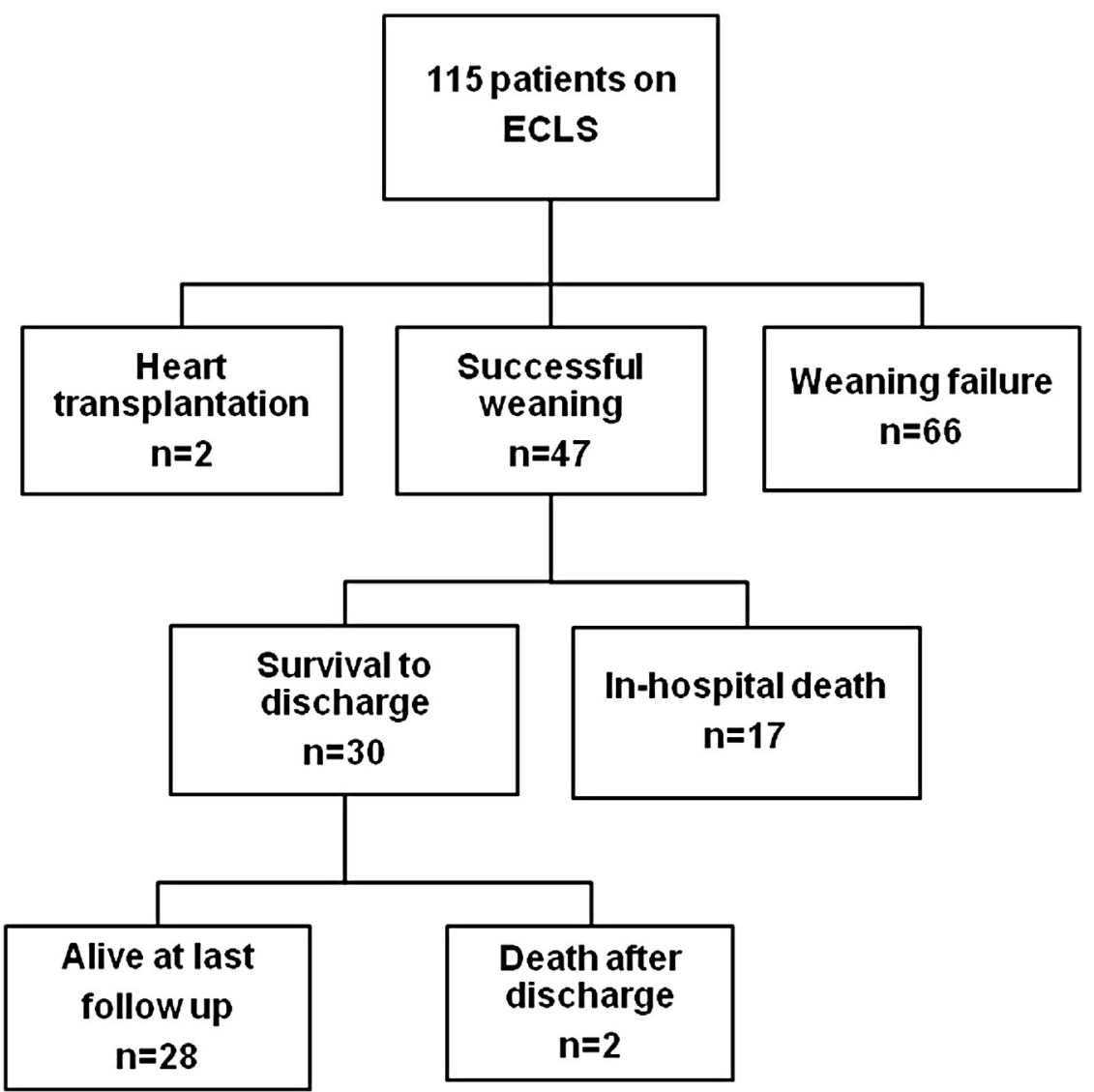

FIGURE 1. Flowchart of the outcomes in patients receiving ECLS. ECLS, Extracorporeal life support. 
TABLE 4. Multivariable risk factors analyses for in-hospital mortality and impact of lactate level on mortality

\begin{tabular}{llll}
\hline \multicolumn{1}{c}{ Variables } & RR & $\mathbf{9 5} \%$ CI & $\boldsymbol{P}$ value \\
\hline Pre-ECLS baseline variables & & & \\
Arterial lactate level before ECLS & 1.19 & $1.06-1.34$ & .003 \\
CPB weaning failure after surgery & 4.39 & $1.44-13.35$ & .009 \\
Arterial lactate levels during ECLS* & & & \\
6 h after ECLS initiation & 1.24 & $1.06-1.46$ & .009 \\
12 h after ECLS initiation & 1.35 & $1.10-1.67$ & .005 \\
24 h after ECLS initiation & 1.46 & $1.10-1.93$ & .008 \\
\hline$C I$, Confidence interval; $C P B$, cardiopulmonary bypass; $E C L S$, extracorporeal life \\
support; $R R$, relative risk. *Adjusted by "arterial lactate level before ECLS" and \\
"CPB weaning failure."
\end{tabular}

hypoxia forces anaerobic metabolism of glucose, which leads to enhanced production of lactate than its removal, resulting in hyperlactatemia. Several studies have shown intimate associations of elevated lactate level with worse outcomes in major cardiac surgery. ${ }^{9,10}$ Increased lactate release during reperfusion after cardioplegic arrest in cardiac surgical patients is known to be an independent predictor of low cardiac output syndrome. ${ }^{3}$ A recent study by Hajjar and colleagues ${ }^{4}$ demonstrated that the lactate level 6 hours after ICU admission is an independent predictor for major complications after cardiac surgery, and they suggested that a strategy of aiming to lower serum lactate level using other hemodynamic parameters may reduce the incidence of major complications after cardiac surgery. Furthermore, a prospective, randomized study demonstrated that normalization of lactate level as a therapeutic goal can shorten the length of hospital day and decrease the morbidity. ${ }^{11}$

Consistent with the cited reports, our previous study showed a close association between high blood lactate level and mortality in patients who underwent ECLS after major cardiac surgery. ${ }^{5}$ High lactate level before ECLS initiation was an independent predictor of mortality, and the lactate level of $7.9 \mathrm{mmol} / \mathrm{L}$ before initiation of ECLS, assessed using the ROC method, was the most accurate predictive value for mortality. This result is supported by other studies. $^{12,13}$

ECLS can provide total circulatory support with fully oxygenated blood so that oxygen delivery and systemic tissue perfusion are satisfied in patients with severe respiratory or circulatory failure. Consequent rapid decrement of lactate level is expected in these patients. Nevertheless, a significant number of patients who underwent ECLS do not seem to show a remarkable decrement in blood lactate level. We hypothesized that the patients who do not show an appropriate decrement in blood lactate level after the initiation of ECLS may have inadequate tissue perfusion related to complications or insufficient support. The present study demonstrated that serially measured arterial blood lactate levels at 6 hours,
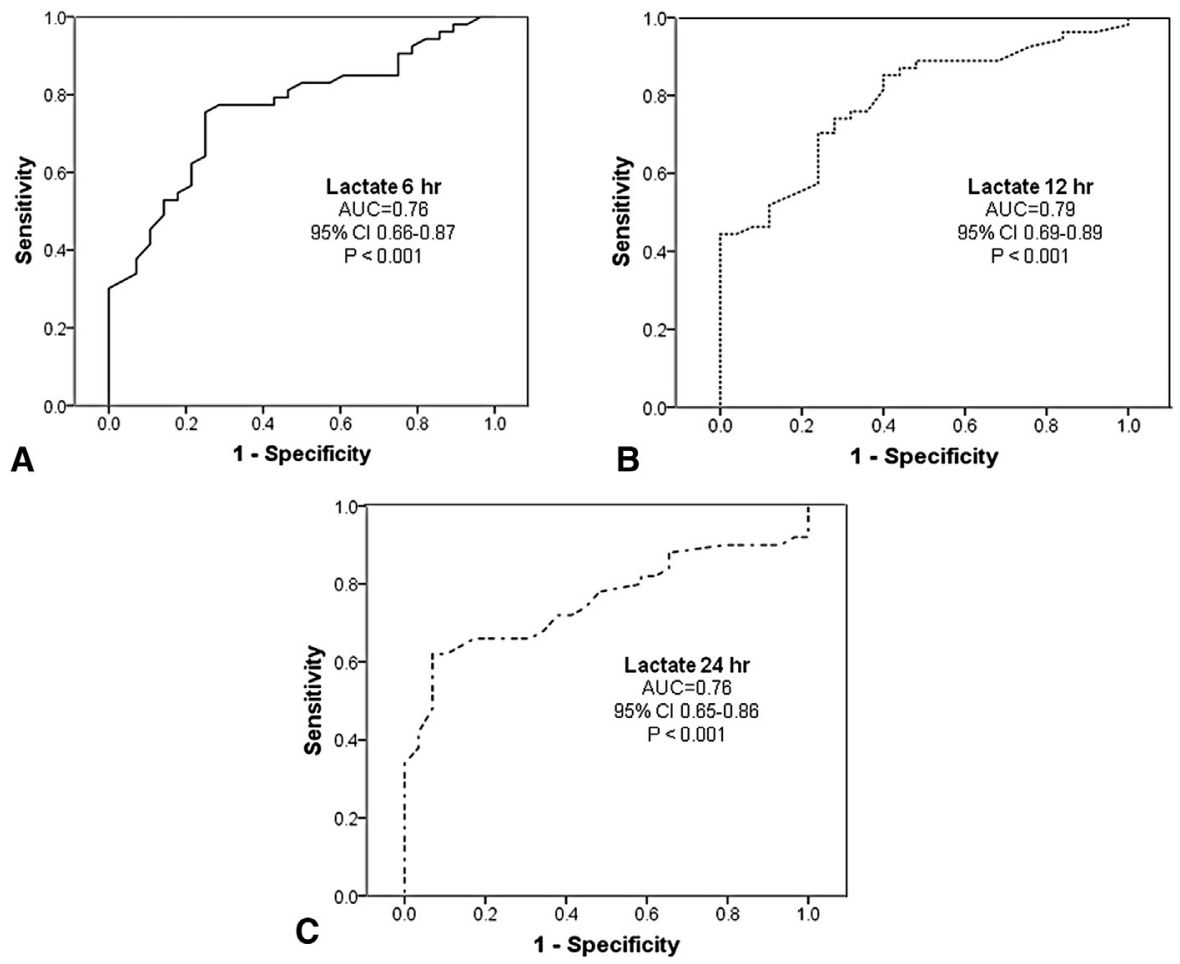

FIGURE 2. ROC curves for the predictive value of arterial lactate level for mortality at 6 hours (A), 12 hours (B), and 24 hours (C) after the initiation of ECLS. AUC, Area under the curve; $C I$, confidence interval. 


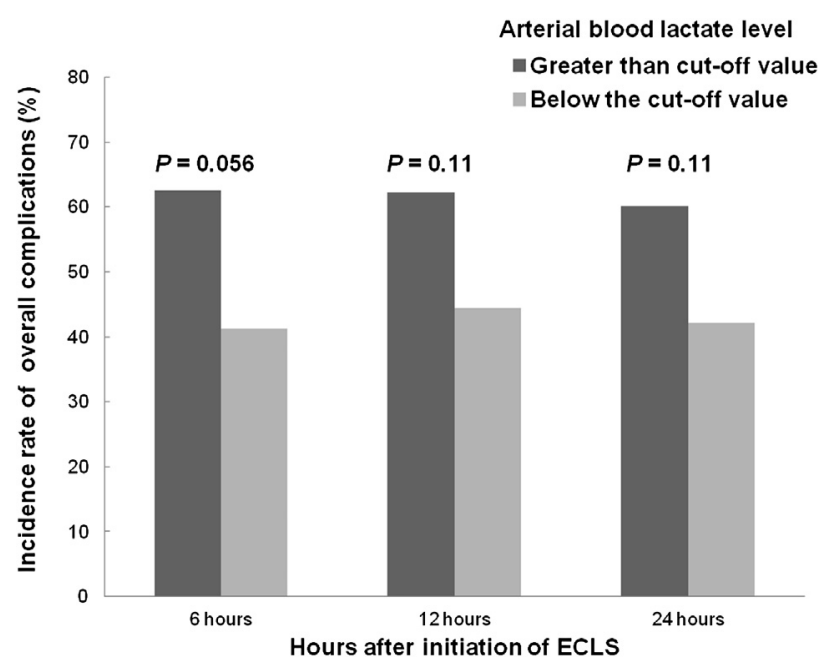

FIGURE 3. The incidence rate of the overall complications according to the cutoff arterial lactate levels at 6 hours, 12 hours, and 24 hours after the initiation of ECLS. ECLS, Extracorporeal life support.

12 hours, and 24 hours after ECLS initiation were independent predictors of mortality even after adjustment with pre-ECLS risk factors. The cutoff values of predictive for mortality gradually declined in serially measured lactate level after ECLS initiation (Figure 2). These findings suggest that the failure to achieve adequate decrement in arterial lactate level shortly after ECLS initiation is associated with increased mortality in patients with hyperlactatemia. Therefore, in patients without an adequate decrement in lactate levels during ECLS, potential factors responsible for inadequate perfusion should be identified and corrected. In these regards, this study proposes arterial lactate measurement as a monitoring tool during ECLS for the acquisition of satisfactory tissue perfusion. Although previous studies also have demonstrated an association between the high blood lactate level after initiation of ECLS and mortality or weaning failure, ${ }^{14-16}$ the cited studies have not shown the predictive role of lactate measurement as a monitoring tool during ECLS.

Chen and colleagues ${ }^{15}$ showed a significant correlation between survival and lactate levels on the first, third, and seventh days of ECLS. Another recent study also demonstrated that patients who survived to discharge showed significantly lower levels of lactate at 48 and 72 hours than nonsurvivors. ${ }^{14}$ Compared with these earlier studies, the present study evaluated the influences of blood
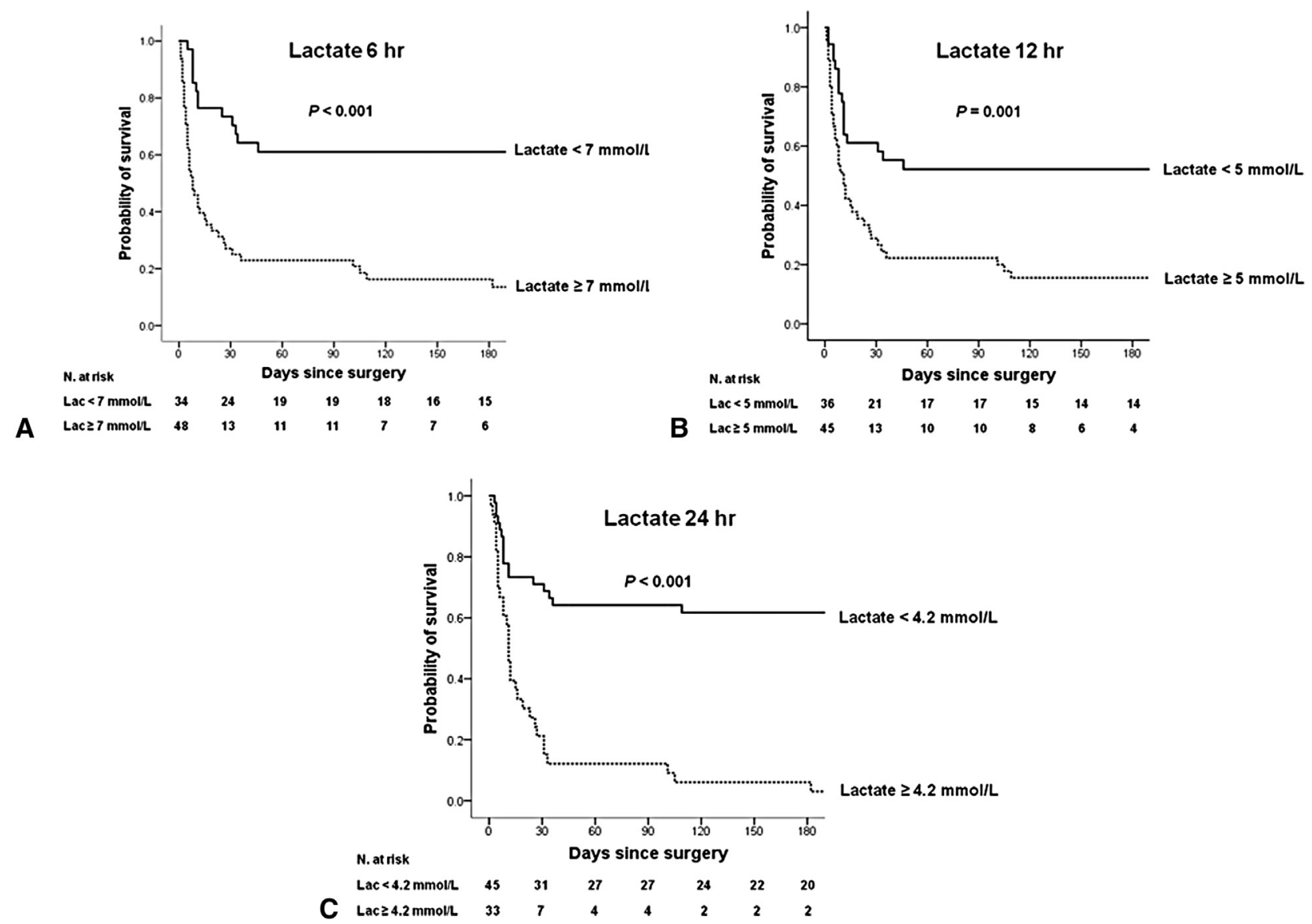

FIGURE 4. Kaplan-Meier analysis revealing differences in mortality according to the arterial lactate level at 6 hours (A), 12 hours (B), and 24 hours (C) after the initiation of ECLS. Lac, Lactate. 
lactate levels focusing more on the very early period (within 24 hours). This is because the postoperative courses of patients who underwent major cardiac surgery are dynamic, especially in those who require ECLS, in that patients' outcomes are likely to be determined in the very early postoperative period. For instance, of 83 patients who died in-hospital in the present study, $23(27.7 \%)$ died within 3 days of ECLS support and 47 (56.6\%) died within 7 days. These findings indicate that referencing the lactate levels at 3 or 7 days is too late for many patients; therefore, we need to establish more reasonable monitoring methods for very early settings. This is why we focused on the relatively earlier period of the course compared with other previous studies.

New techniques, such as laser-Doppler flowmetry, near-infrared spectroscopy, and sidestream dark-field imaging, have been introduced to evaluate tissue perfusion and microcirculation at the bedside. ${ }^{17-19}$ Although these techniques might be used as a tailored therapy in the foreseeable future, practical application of these equipment and techniques during ECLS in a routine way may not be feasible because of the associated costs.

\section{Study Limitations}

This study is subject to the limitations inherent in retrospective studies of observational data from a single center. The study failed to elucidate the direct relation between the elevated lactate level after the initiation of ECLS and each complication during ECLS, such as hemorrhage, bowel ischemia, cannulation-related, and device-related complications. This may account for the relatively small number of patients who experienced each complication.

Lactate level-guided intervention during ECLS is an important issue according to the study results. However, the present study could not evaluate whether lactate level-guided intervention decreased mortality. To address this issue, "intention-to-treat" basis analyses should be performed, which is only possible through studies with prospective designs.

\section{CONCLUSIONS}

Establishment of reliable markers to monitor adequate tissue perfusion during ECLS is clinically important to improve outcomes. Arterial lactate level after the initiation of ECLS is strongly predictive of mortality and has the tendency to decrease sequentially in patients acquiring satisfactory tissue perfusion. Therefore, arterial lactate measurement can be used as a valuable and reliable tool for monitoring adequate tissue perfusion during ECLS. In patients without adequate decrement in lactate levels during ECLS, potential factors responsible for inadequate perfusion should be identified and corrected. Prospective, randomized studies targeting normalization of the lactate level as a therapeutic goal are required to verify the impact of post-ECLS arterial lactate measurement on the outcomes of ECLS.

\section{References}

1. Li J, Schulze-Neick I, Lincoln C, Shore D, Scallan M, Bush A, et al Oxygen consumption after cardiopulmonary bypass surgery in children: determinants and implications. J Thorac Cardiovasc Surg. 2000;119:525-33.

2. Pietersen HG, Langenberg CJM, Geskes G, Kester A, de Lange S, Van der Vusse GJ, et al. Myocardial substrate uptake and oxidation during and after routine cardiac surgery. J Thorac Cardiovasc Surg. 1999;118:71-80.

3. Rao V, Ivanov J, Weisel RD, Cohen G, Borger MA, Mickle DA. Lactate release during reperfusion predicts low cardiac output syndrome after coronary bypass surgery. Ann Thorac Surg. 2001;71:1925-30.

4. Hajjar LA, Almeida JP, Fukushima JT, Rhodes A, Vincent JL, Osawa EA, et al High lactate levels are predictors of major complications after cardiac surgery. J Thorac Cardiovasc Surg. 2013;146:455-60.

5. Park SJ, Kim JB, Jung SH, Choo SJ, Chung CH, Lee JW. Outcomes of extracorporeal life support for low cardiac output syndrome after major cardiac surgery. J Thorac Cardiovasc Surg. 2014;147:283-9.

6. Stergiopulos N, Westerhof N. Determinants of pulse pressure. Hypertension. 1998;32:556-9.

7. Park BW, Seo DC, Moon IK, Chung JW, Bang DW, Hyon MS, et al. Pulse pressure as a prognostic marker in patients receiving extracorporeal life support. Resuscitation. 2013;84:1404-8.

8. Astiz ME, Rackow EC. Assessing perfusion failure during circulatory shock Crit Care Clin. 1993;9:299-312.

9. Munoz R, Laussen PC, Palacio G, Zienko L, Piercey G, Wessel DL. Changes in whole blood lactate levels during cardiopulmonary bypass for surgery for congenital cardiac disease: an early indicator of morbidity and mortality. J Thorac Cardiovasc Surg. 2000;119:155-62.

10. Maillet JM, Le Besnerais P, Cantoni M, Nataf P, Ruffenach A, Lessana A, et al. Frequency, risk factors, and outcome of hyperlactatemia after cardiac surgery. Chest. 2003;123:1361-6.

11. Polonen P, Ruokonen E, Hippelainen M, Poyhonen M, Takala J. A prospective, randomized study of goal-oriented hemodynamic therapy in cardiac surgical patients. Anesth Analg. 2000;90:1052-9.

12. Chen JS, Ko WJ, Yu H, Lai LP, Huand SC, Chi NH, et al. Analysis of the outcome for patients experiencing myocardial infarction and cardiopulmonary resuscitation refractory to conventional therapies necessitating extracorporeal life support rescue. Crit Care Med. 2006;34:950-7.

13. Li J, Long C, Lou S, Hei F, Yu K, Wang S, et al. Venoarterial extracorporeal membrane oxygenation in adult patients: predictors of mortality. Perfusion. 2009;24:225-30.

14. Formica F, Avalli L, Colagrande L, Ferro O, Greco G, Maggioni E, et al. Extracorporeal membrane oxygenation to support adult patients with cardiac failure: predictive factors of 30-day mortality. Interact Cardiovasc Thorac Surg. 2010;10:721-6.

15. Chen US, Chao A, Yu HY, Ko WJ, Wu IH, Chen RU, et al. Analysis and results of prolonged resuscitation in cardiac arrest patients rescued by extracorporeal membrane oxygenation. J Am Coll Cardiol. 2003;41:197-203.

16. Hsu PS, Chen JL, Hong GJ, Tsai YT, Lin CY, Lee CY, et al Extracorporeal membrane oxygenation for refractory cardiogenic shock after cardiac surgery: predictors of early mortality and outcome from 51 adult patients. Eur J Cardiothoracic Surg. 2010;36:328-33.

17. den Uil CA, Lagrand WK, Valk SD, Spronk PE, Simoons ML. Management of cardiogenic shock: focus on tissue perfusion. Curr Probl Cardiol. 2009;34: $330-49$.

18. Hoff DA, Gregersen H, Hatlebakk JG. Mucosal blood flow measurements using laser Doppler perfusion monitoring. World J Gastroenterol. 2009;15: 198-203.

19. Struijker-Boudier HA, Rosei AE, Bruneval P, Camici PG, Christ F, Henrion D, et al. Evaluation of the microcirculation in hypertension and cardiovascular disease. Eur Heart J. 2007;28:2834-40. 